\title{
ПЕРВАЯ НАХОДКА ТВЕРДЫХ РАСТВОРОВ ТОРИТА И КСЕНОТИМА В МЕТАПЕЛИТОВЫХ ГРАНУЛИТАХ КУРСКО-БЕСЕДИНСКОГО БЛОКА (ВОРОНЕЖСКИЙ КРИСТАЛЛИЧЕСКИЙ МАССИВ)
}

\author{
С. М. Пилюгин
}

\author{
Воронежский государственный университет
}

Поступила в редакцию 19 ноября 2019 г.

\begin{abstract}
Аннотация: в метапелитах Курско-Бесединского блока Воронежского кристаллического массива методами растровой электронной микроскопии и энергодисперсионного микроанализа были обнаружены два уникальных зерна торит-ксенотимовых твердых растворов. Они представляют собой мелкие (20-30 мкм) округлые выделения, локализуюшчеся в полевошпатовой матрице. Зерно №1 представляет собой природный эталон полной смесимости торита и ксенотима. Зерно № 2 обогащено торитовым миналом. Примеси воды, фиксируемые в анализируемых зернах, расширяют поля смесимости многокомпонентных минеральных систем. Источником минерального вещества для торит-ксенотимовых твердых растворов являлись гидротермы, проникающие по трещинам и тонким каналам в породе. Выделения галенита в структуре изученных твердых растворов являются препятствием для определения возраста геологических прочессов методом СНIME. Ключевые слова: Воронежский кристаллический массив, мезоархей, метапелитовые гранулиты, твердые растворы, торит, ксенотим.
\end{abstract}

\section{THE FIRST FIND OF SOLID SOLUTIONS THORITE AND XENOTIME IN METAPELITE GRANULITES OF THE KURSK-BESEDINO BLOCK (VORONEZH CRYSTALLINE MASSIF)}

\author{
S. M. Pilyugin \\ Voronezh State University \\ Received 19 Novtember 2019
}

\begin{abstract}
: two unique grains of thorite-xenotime solid solutions solutions were found in metapelites of the Kursk-Besedino block (Voronezh crystalline massif). They are small (20-30 microns) roundish discharge localized in the feldspar matrix. Grain No. 1 is a natural standard for the complete miscibility of thorite and xenotime. Grain No. 2 is enriched with a thorite mineral. Water fixed in the analyzed grains expands the polar mixtures of multicomponent mineral systems. The source of minerals for thorite-xenotime solid solutions are hydrotherm penetrating through cracks and thin channels in the rock. The precipitation of galena in the structure of the studied solid solutions is an obstacle to determining the age of geological processes by the CHIME method.
\end{abstract}

Keywords: Voronezh Crystalline Massif, mesoarchean, metapelite granulites, solid solutions, thoritexenotime.

\section{Введение}

За последнее десятилетие в пределах Воронежского кристаллического массива (ВКМ) были обнаружены редкие, а в некоторых случаях даже уникальные минеральные парагенезисы. Во многом, это связано с применением современных прецизионных методов изучения геологических объектов на микроуровне (растровая электронная микроскопия, энегодисперсионный и волновой рентгеноспектральный микроанализ).

Вместе с тем, по ряду причин (ограниченность фактического материала, непредставительность взя- 
тых проб, наноразмерность минеральных агрегатов) всегда существует вероятность фиксации в породах ранее не исследованных минеральных фаз. Одним из таких объектов, описываемых в настоящей работе, являются твердые растворы смешанного (Si-P) состава, обнаруженные при электронно-микроскопических исследованиях метапелитов Курско-Бесединского блока ВКМ.

\section{Геологическое положение}

Два зерна твердых растворов были зафиксированы в керне скважины 3555, глубина 203 м, пробуренной в пределах Ушаковских магнитных аномалий КурскоБесединского блока ВКМ (рис. 1).

Курско-Бесединский блок сложен биотитовыми, биотит-роговообманковыми плагиогнейсами с маломощными прослоями роговообманковых амфиболитов, часто мигматизированных и гранитизированных. В пределах гнейсового комплекса на фоне общего мозаичного поля выделяются интенсивные положительные магнитные аномалии эллипсовидной, серповидной и полосовидной формы, сложенные комплексом разнообразных пород, претерпевших метаморфизм в условиях гранулитовой фации. Их

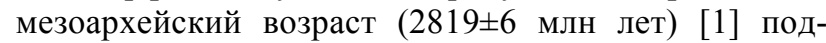
твержден геохронологическими определениями по монациту (U-Pb изохронный метод) из метапелитовых гранулитов, переслаивающихся в разрезе с железистыми кварцитами.

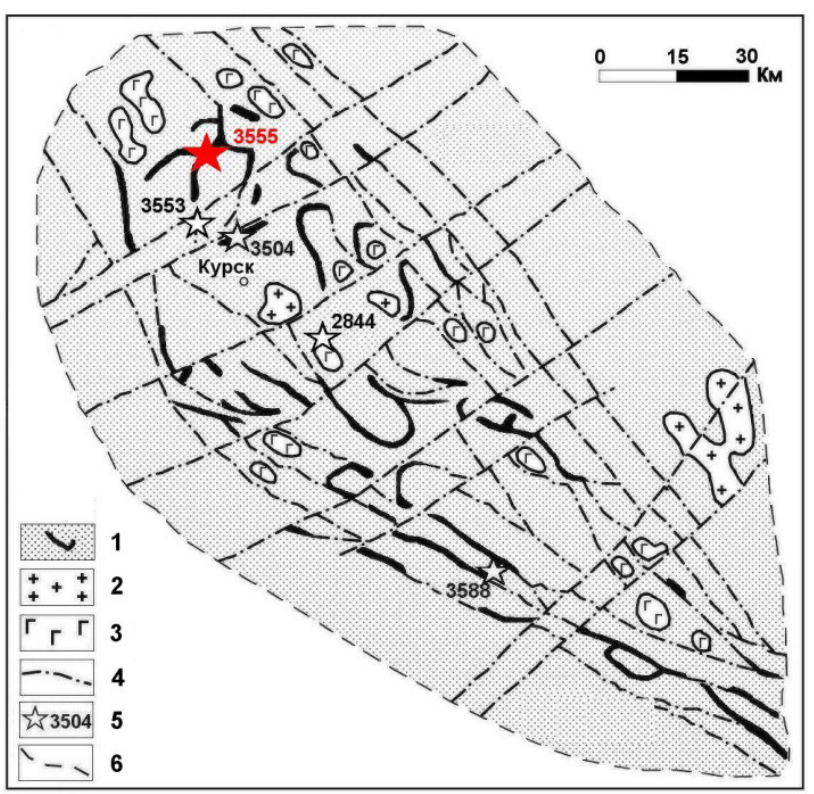

Puc. 1. Курско-Бесединский блок ВКМ (район исследования): 1 - высокотемпературные метаморфические комплексы (метапелиты, метабазиты, метаультрабазиты) с железистыми формациями; 2 - поздне - и посттектонические щелочные и полевошпатовые лейкократовые гранитоиды; 3 - габброиды; 4 - зоны глубинных разломов; 5 - местоположение скважин; 6 границы Курско-Бесединского блока. Красным цветом выделена исследованная скважина.

\section{Методы исследования}

Обнаруженные зерна твердых растворов были изучены на растровом электронном микроскопе Jeol6380 LV (ЦКПНО ВГУ); химический состав фаз определялся при помощи полупроводникового детектора INCA x-sight EDS 250, смонтированного на электронном микроскопе. Условия анализа: ускоряющее напряжение 20 кВ, ток зонда 10-15 нА, время набора спектра в зависимости от задач варьировало от 70 до 150 сек., диаметр электронного пучка в приповерхностном слое образца обычно равнялся 3-5 мкм.

ZAF коррекция при расчете содержания окислов и оценка точности проводились с помощью комплекта программ математического обеспечения системы. Точность анализа систематически контролировалась по эталонным образцам природных и синтетических минералов.

Кристаллохимические формулы рассчитаны на 4 атома кислорода, оптимизация данных, полученных в результате микрозондовых анализов, была проведена на базе программы «MinFile».

\section{Полученные результаты}

Твердые растворы представляют собой округлые, мелкие (20х30 мкм) выделения с неровными слабо корродированными границами (рис. 2a). Для зерна № 1 матричными являются плагиоклаз (андезин) и железистый биотит; зерно № 2 полностью оконтурено каймой железистого хлорита (рис. 2a). Оба изученных зерна пересекаются тонкими трещинами и ответвлениями, уходящими за их границы. Высококонтрастная съемка позволила установить неоднородности внутреннего строения зерен - наличие в них мельчащих (<1 мкм) выделений, отвечающих по составу предположительно галениту (рис. 2б).

По химическому составу (табл. 1) изученные зерна представляют собой твердые минеральные растворы ряда торит-ксенотим. Торит изоструктурен с ксенотимом (тетрагонален) поэтому может образовывать твердые растворы с механизмом компенсационного парного замещения: $\mathrm{Th}^{+4}+\mathrm{Si}^{+4}=\mathrm{Y}, \operatorname{HREE}^{+3}+\mathrm{P}^{+5}[2,3]$. Следует отметить, что ранее подобные (за некоторым исключением) твердые растворы были описаны только в гранитоидах Германии и Иордании [4]. В метаморфических породах ВКМ рядом авторов [5] были изучены твердые растворы системы торит-циркон и торит-коффинит.

Исходя из данных химического анализа (табл. 1) обнаруженные зерна представляют собой различные по смесимости минеральные системы: зерно № 2 по сравнению с зерном № 1 обогащено торитовым миналом (64 \% против $50 \%$ ); твердый раствор, слагающий зерно № 1, представляет собой природный эталон полной смесимости торита и ксенотима (Рис. 3).

В изученных твердых растворах отмечаются примеси воды (заниженные суммы в составе), которая играет важную роль в расширении полей смесимости многокомпонентных минеральных систем. 

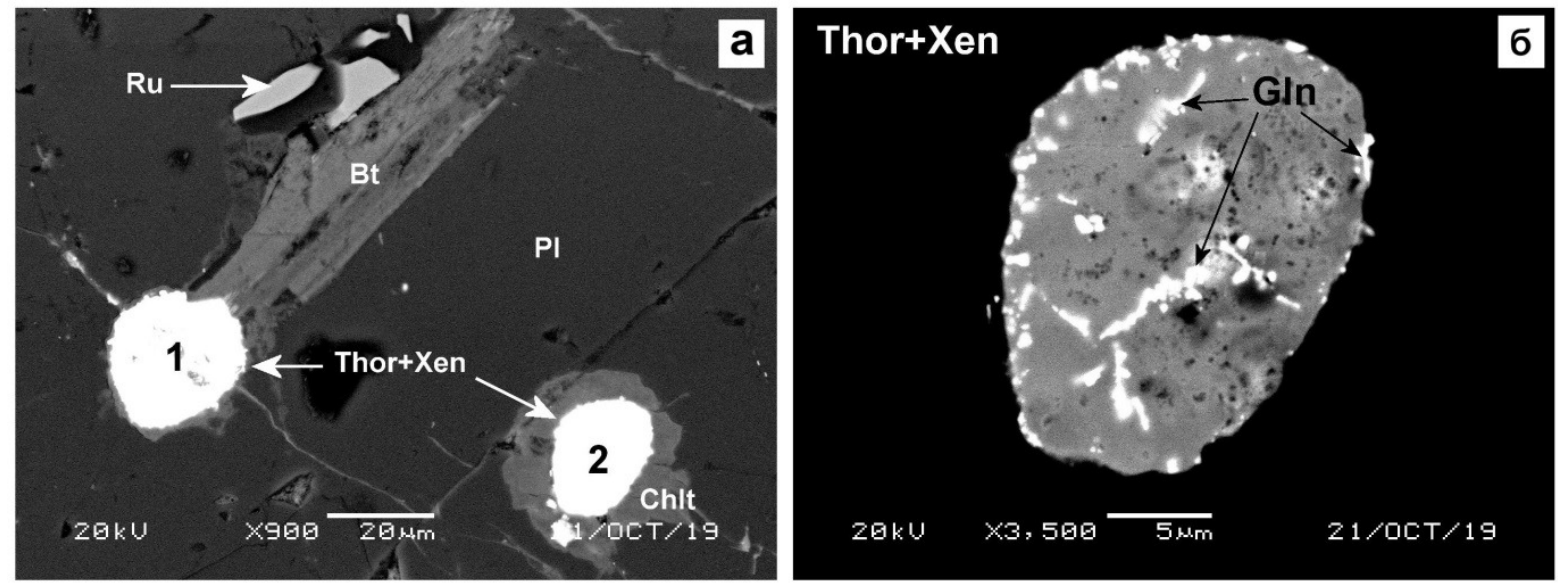

Puc. 2. Электронно-микроскопические фотографии торит-ксенотимовых твердых растворов (изображения в обратноотраженных электронах): $a$ - твердые растворы торит-ксенотим (Thor+Xen) (зерно №1, №2) в ассоциации с плагиоклазом (Pl), хлоритом (Chlt), биотитом (Bt) и рутилом (Ru); $\sigma$ - выделения галенита (Gln) в твердом растворе торит-ксенотим (зерно №2).

Химические составы торит-ксенотимовых твердых растворов

\begin{tabular}{|c|c|c|}
\hline Зерно № & $1 *$ & $2 * *$ \\
\hline $\mathrm{SiO}_{2}$ & 14,28 & 18,24 \\
\hline $\mathrm{P}_{2} \mathrm{O}_{5}$ & 9,24 & 5,21 \\
\hline $\mathrm{CaO}$ & 1,30 & 0,75 \\
\hline $\mathrm{FeO}$ & 2,31 & 2,34 \\
\hline $\mathrm{Y}_{2} \mathrm{O}_{3}$ & 21,06 & 17,25 \\
\hline $\mathrm{Dy}_{2} \mathrm{O}_{3}$ & 1,98 & 3,71 \\
\hline $\mathrm{Er}_{2} \mathrm{O}_{3}$ & 2,60 & 2,11 \\
\hline $\mathrm{Yb}_{2} \mathrm{O}_{3}$ & 2,04 & 1,38 \\
\hline $\mathrm{PbO}$ & 1,65 & 1,10 \\
\hline $\mathrm{ThO}_{2}$ & 31,11 & 42,83 \\
\hline Сумма & 87,57 & 94,92 \\
\hline $\mathrm{Si}$ & 0,66 & 0,84 \\
\hline $\mathrm{P}$ & 0,36 & 0,20 \\
\hline $\mathrm{Ca}$ & 0,06 & 0,04 \\
\hline $\mathrm{Fe}$ & 0,09 & 0,09 \\
\hline $\mathrm{Y}$ & 0,52 & 0,42 \\
\hline Dy & 0,03 & 0,05 \\
\hline $\mathrm{Er}$ & 0,04 & 0,03 \\
\hline $\mathrm{Yb}$ & 0,03 & 0,02 \\
\hline $\mathrm{Pb}$ & 0,02 & 0,01 \\
\hline Th & 0,33 & 0,45 \\
\hline Total & 2,15 & 2,15 \\
\hline $\mathrm{O}$ & 4,00 & 4,00 \\
\hline $\mathrm{Th}+\mathrm{Si}$ & 0,99 & 1,29 \\
\hline $\mathrm{Y}+\mathrm{P}+\mathrm{HREE}$ & 0,98 & 0,72 \\
\hline Thor & $50 \%$ & $64 \%$ \\
\hline Xen & $50 \%$ & $36 \%$ \\
\hline
\end{tabular}

Примечания: * - среднее по 7 анализам; ** - среднее по 9 анализам.

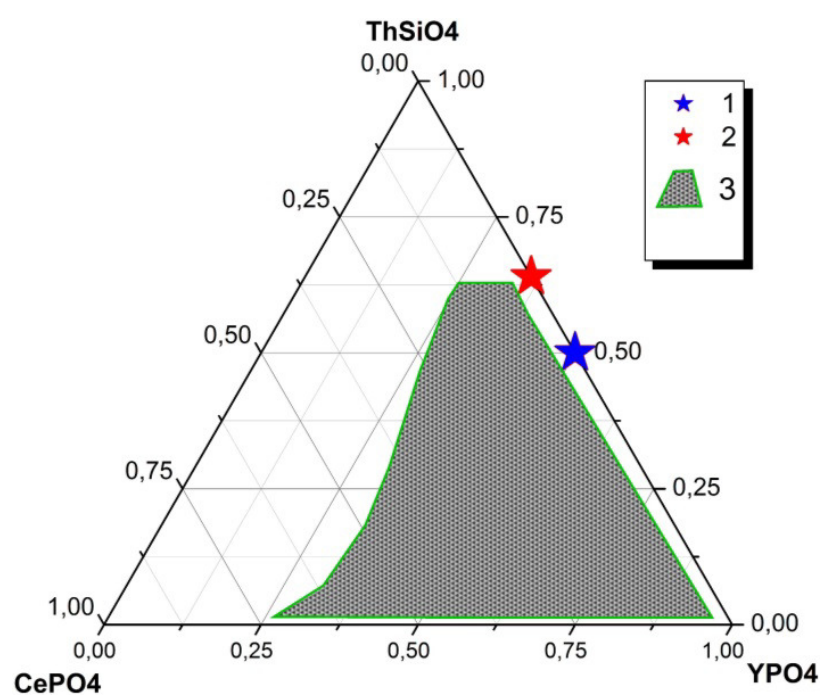

Рuc. 3. Положение составов твердых растворов на треугольной диаграмме в системе «монацит - ксенотим - торит (хаттонит)»: 1 - зерно № 1;2 - зерно № 2; 3 - метастабильная область существования составов.

К примеру, экспериментальные исследования систем циркон-торит (коффинит) [6], циркон-ксенотим [7] показали разрыв смесимости на уровне 15 мол, \%, что опровергается исследованиями природных твердых растворов [4]. Такой парадокс, вероятно, является следствием простых (беспримесных) и безводных минеральных систем, применяющихся при проведении экспериментов.

\section{Заключение}

Считается, что образование метастабильных промежуточных твердых минеральных растворов обязано быстрому охлаждению горных пород [8]. Ранее [9], для мезоархейских гранулитов Курско-Бесединского блока ВКМ был построен тренд эволюции с несколькими стадиями метаморфизма, разделенными периодами изотермической декомпрессии и изобарического охлаждения. Вероятно, наблюдаемые в изучаемых 
метапелитах твердые растворы сформировались в один из этапов изобарического охлаждения на ретроградной стадии метаморфизма. Источником минерального вещества для изученных зерен, по аналогии с гранитными массивами [4] могли послужить гидротермы с активным (F, $\mathrm{CO}_{2}, \mathrm{H}_{2} \mathrm{O}$ ) флюидом, проникающие по трещинам и тонким каналам в породе.

Еще одним аспектом изучения обнаруженных твердых растворов является наличие в них мельчащих кристаллов галенита. В последнее время в петрологии активно используется метод химического датирования (CHIME), в основе которого лежит предположение о радиогенной природе свинца в минералахгеохронометрах (монацит, ксенотим и др.). Наличие в таких индикаторных минералах примесей серы [10] или свинцовых выделений (рис. 2б) делает некорректным их применение для определения возраста геологических процессов.

\section{ЛИТЕРАТУРА}

1. Возраст метаморфизма гранулитовых комплексов ВКМ: результаты U-PB геохронологических исследований монацита / К. А. Савко [и др.] // Доклады Академии наук. Сер. Геология. - 2010. - Т. 435. - № 5. - С. 1-6.

2. Дир, У. А. Породообразующие минералы / У. А. Дир, Р. А. Хауи, Дж. Зусман // Издательство «Мир». - 1966. - Т. 5. - С. 379.

\section{ФГБОУ ВО Воронежский государственный университет}

Пилюгин Сергей Михайлович, кандидат геологоминералогических наук, доиент кафедры полезных ископаемых и недропользования

E-mail: geoscience@yandex.ru

Тел.: +7 (473) 2208626
3. Kohn, M. J. Phosphates. Geochemical, Geobiological and Material Importance / M. J. Kohn, J. Rakovan, J. Hughes // Mineral. Soc. Of Am. - 2003. - V. 48. - P. 1-99.

4. Foster, H. -J. Composition and origin of intermediate solid solutions in the system thorite-xenotime-zircon-coffinite / H. J. Fosrter // Lithos. - 2005. - V. 88. - P. 35-55.

5. Фазовые равновесия редкоземельных минералов при метаморфизме углеродистых сланцев Тим-Ястребовской структуры, Воронежский кристаллический массив / К. А. Савко [и др.] // Петрология. - 2010. - Т. 18. - № 4. - С. 402-433.

6. Mumpton, F. A. Hydrothermal stability studies of the zirconthorite group / F. A. Mumpton, R. Roy // Geochimica Cosmochimica Acta. - 1961. - V. 21 - P. 217-238.

7. Rare earth elements in synthetic zircons: Part 1. Synthesis, and rare earth element and phosphorus doping / J. M. Hanchar [et al.] // American Mineralogist - 2001. - V. 86 - P. 667-680. 8. Pointer, C. M. The zircon-thorite mineral group in metasomatized granite, Ririwai, Nigeria 1. Geochemistry and metastable solid solution of thorite and coffinite / C. M. Pointer, J. R. Ashworth, R. A. Ixer // Mineralogy and Petrology - 1988a. - V. 38 - P. 245-262.

9. Пилюгин, С. М. Глиноземисто-железистые породы Курско-Бесединского гранулитового блока ВКМ (физикохимические условия метаморфизма, тренд тектонотермальной эволюции) / С. М. Пилюгин // Вестник Воронеж. гос. ун-та. Серия Геология. - 2010. - №2. - С.147-158.

10. Sulfur-rich monazite with high common $\mathrm{Pb}$ in ore-bearing schists from the Schellgaden mining district (Tauern Window, Eastern Alps) / E. Krenn [et al.] // Miner. Petrol. - 2011 - V. $102-$ P. 51-62.

\section{Voronezh State University}

Pilyugin S. M., Candidate of Geological and Mineralogical Sciences, associate Professor of the Mineral Resource Department

E-mail: geoscience@yandex.ru Tel.: +7 (473) 2208626 